\title{
ИНТЕНСИВНОСТЬ ТУРБУЛЕНТНОСТИ В ШАХМАТНОМ ПУЧКЕ ТРУБ В УСЛОВИЯХ НЕСИММЕТРИЧНЫХ ПУЛЬСАЦИЙ ПОТОКА
}

\author{
Савельева А.Д. \\ ФГБОУ ВО «Казанский государственный \\ энергетический университет», г. Казань, Россия
}

Теплообменные аппараты с трубными пучками широко распространены в топливно-энергетическом комплексе. Поэтому исселдование характеристик течения в аппаратах данного типа является актуальной задачей. Данная работа посвящена исследованию турбулентности в пучке труб при наложенных пульсачиях потока. В работе представленны результаты математического маделирования проведенного $c$ помощью программы вычислительной гидродинамики AnsysFluent. Численное исследование проводилось в шахмотном пучке труб. Количество рядов по ходу жидкости состовляло семь. Пульсаиий потока имели несимметричных характер с возратно поступательным движением потока жидкости.

Ключевые слова: возратно поступальные пульсации, несимметричные пульсации, вычислительная гидродинамика, пучок труб, кожухотрубный теплообменник, интенсивность турбулентнсоти

Кожухотрубное теплообменное оборудование имеет широкое приминение во всех отраслях промышленности. Основным элементом теплообменников данного типа является трубный пучок. Теплообмен между двумя средами осуществляется через стенки трубок. Один из теплоносителей циркулируюет внутри трубок (трубное пространство), другой снаружи трубок (межтрубное пространство). Течение в межтрубном пространстве происходит при поперечном обтекании пучка.

Для повышения эффективности трубчатых теплообменных аппаратов применяют различные перспективные методы интнесификации теплообмена, как для трубного пространства $[1,2]$, так и для межтрубного $[3,4]$. На сегодняшний день одним из перспективных методов интенсификации теплообмена является пульсация потока [5].

Использованию вынужденных пульсаций потока как спопособ интенсификации теплообмена посвящено множество работ [6]. Однако работы, в которых исследуюется пульсируюещие потоки в пучках труб имеют ограниченный характер [7-9]. Поэтому необходимо продолжить исследования в данной области.

Для проведения математического моделирования была построина двухмерная область состоящая и семи рядов трубок (рис. 1). Трубки в пучке были расположены в шахматном порядке. Диаметор трубок $D=20$ мм. Поперчный и продольный шаг $S_{1,2}=26$ мм. 


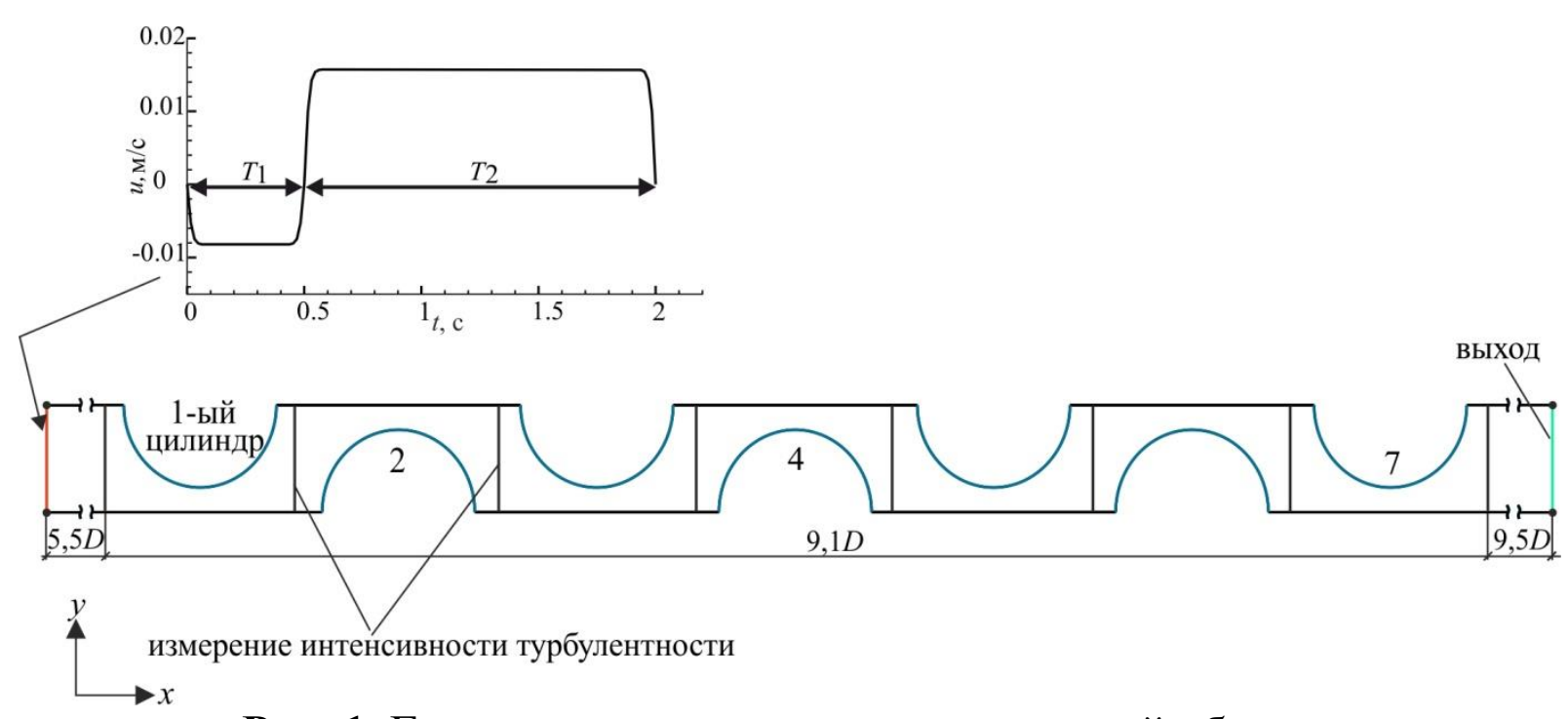

Рис. 1. Геометрические параметры расчетной области

Численное исследование проводилось при следующих граничных условиях:

- на входе при стационарном течени задавалась постоянная скорость потока ( $u=$ const);

- на выходе задавалась давление окружающей среды ( $P=$ const);

- расстояние между трубками сверху и снизу расчетной области условие симметрие.

- на входе при пульсацонном течени задавалась пульсация скорости.

Частота пульсаций находилась следующим образом $f=1 / T$ Гц, где $T=T_{1}+T_{2}$ период пульсаций состоящий из двух полупериодов.

Математическое моделирование проводилось на основе програмного продукта вычислительной гидродинамики AnsysFluent. Для дискретизации уравнений Навье-Стокса применялся метод конечных объемом. Для моделирования турбулентности использовалась $k$ - $\varepsilon$ модель с расширенным пристеночным моделированием. Количество контрольных объемов расчетной сетки равнялось 207953. Расчеты проводились при числе Рейнольдса $R e=1100$, числе Прандтля $\operatorname{Pr}=5,1$, безразмерной относительной амплитуде пульсаций $A / D=0,2$, частоте пульсаций $f=0,5$ Гц, и скважности пульсаций $\psi=T_{1} / T=0,25$, период пульсаций $T=2 \mathrm{c}$.

На рис. 2-4 представлена изменение интенсивности турбулентности в пульсирующем течении по сравнению со стацинарным потоком для разных моментов врмемени пульсирующего потока. Интенсивность турбулентности фиксировалась за каждым цилиндром по линиям показанным на рис. 1. Существенное увеличение турбулентности при наложении пульсаций наблюдается за первым цилиндром в пучке для всех представленных моментнов времени. Когда $t / T=0$ отношение $\mathrm{Tu}_{\text {нс }} / \mathrm{Tu}_{\text {ст }}$ увеличивается до 7,17 раза. При $t / T=0,1$ отношение $\mathrm{Tu}_{\mathrm{Hc}} / \mathrm{Tu}_{\text {ст }}$ увеличивается до 10,77 раза и при $t / T=0,62$ до 13,96 раза. Увеличение турбулентности за другими цилиндрами менее значительно. Для цилиндров 2-6 увеличение прироста интенсивности турбулентности $\mathrm{Tu}_{\text {нс}} / \mathrm{Tu}_{\text {ст }}$ составляет около 1,5 , при этом имеются области, при 
которых наблюдается ухудшение турбулентности. Интенсивность турбулентности за последним цилиндром увеличивается до 5,11 раза при $t / T=0,1$.

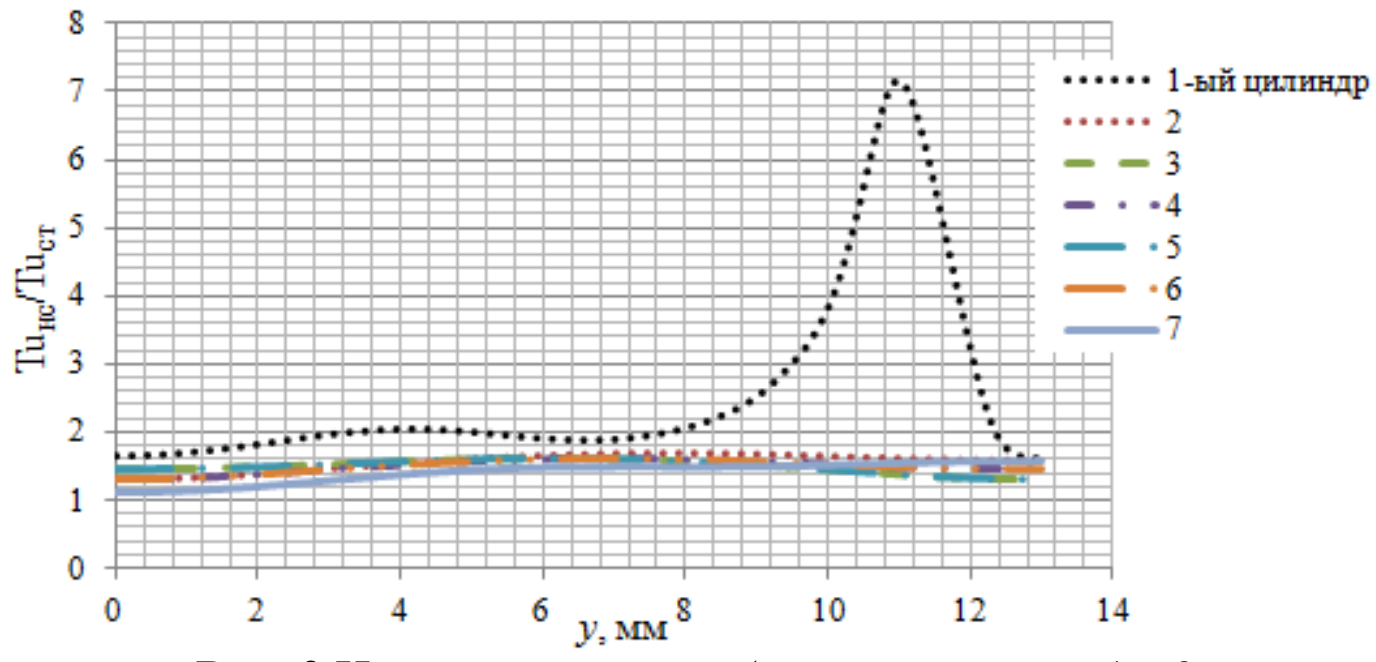

Рис. 2 Интенсивность турбулентности для $t / T=0$

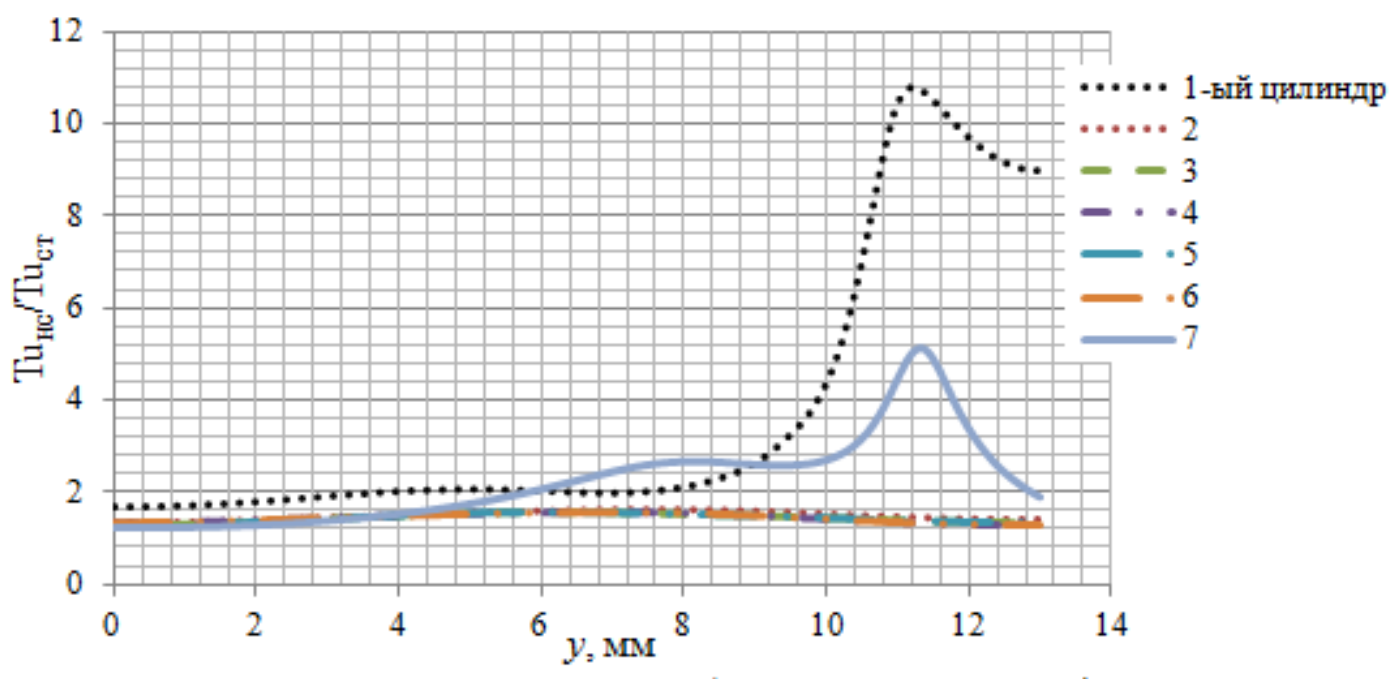

Рис. 3 Интенсивность турбулентности для $t / T=0,1$

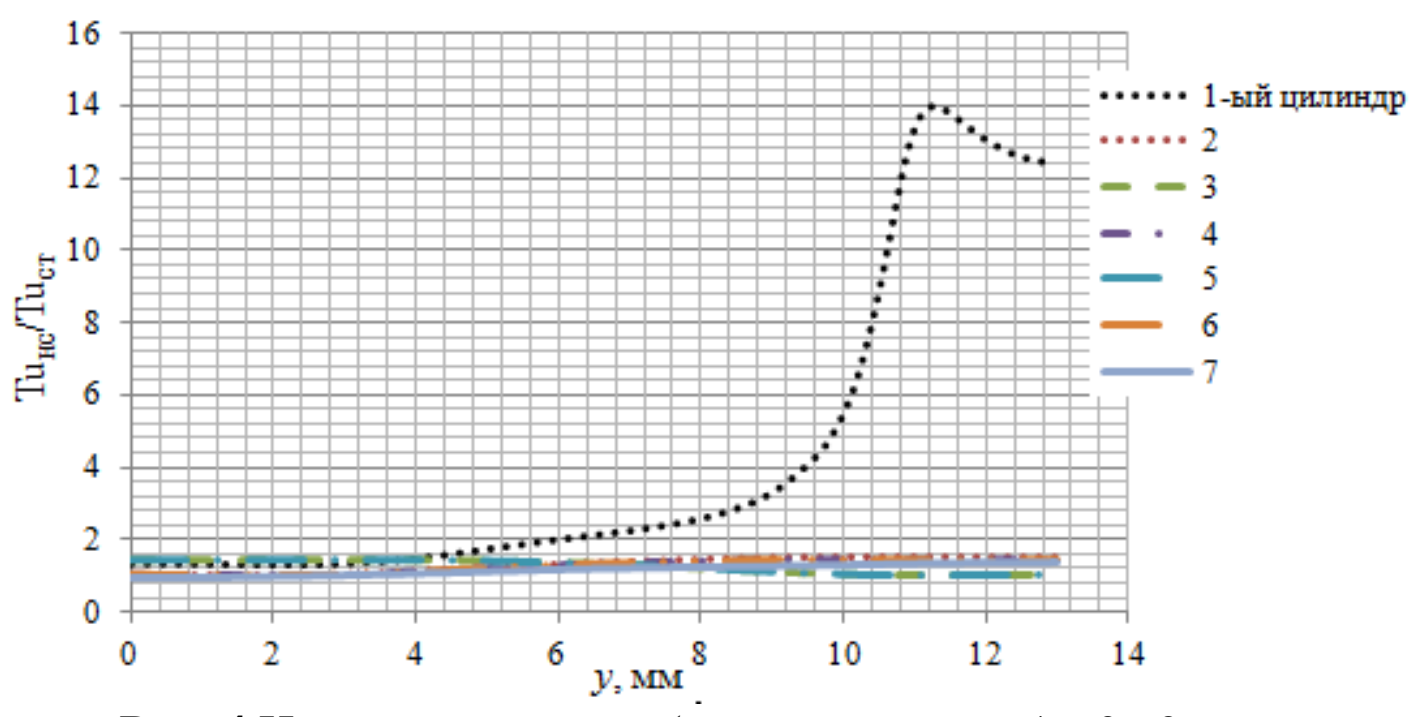

Рис. 4 Интенсивность турбулентности для $t / T=0,62$ 
Несимметричные пульсаций оказывают влияние на степень турбулентности в шахматном пучке труб. Изменение мгновенной интенсивности турбулентности различно по глубине пучка труб и значения пульсирюущей скорости для данного моментна времени на входе пучка.

Известно, что турбулентность первых рядов в стационарном течении в пучке труб всегда ниже последующих [10]. При этом максимальное увеличение турбулентности в 13,96 раза при пульсирующем течении наблюдалось за первым цилиндром при $t / T=0,62$. Также известно, что степень турбулентности влияет на теплоотдачу [10]. Поэтому можно предположить, что наложение пульсаций приведет к росту теплоотдачи пучка, что проявится в большей степени для первого ряда в пучке.

\section{Список литературы}

1. Skrypnik A.N., Shchelchkov A.V., Popov I.A., Ryzhkov D.V, Sverchkov S.A., Zhukova Yu.V., Chornyi A.D., Zubkovc N.N. Thermohydraulic efficiency of tubes with internal spiral finning // J. Eng. Phys. Thermophys. 2018. Vol. 91. № 1. P. $52-63$.

2. Попов И.А., Щелчков А.В., Яркаев М.3., Аль-Джанаби А.Х.А., Скрыпник А.Н. Теплообменные аппараты с интенсификацией теплоотдачи // Энергетика Татарстана. 2014. Т. 33. № 1. С. 10-16.

3. Pongsoi P., Pikulkajorn S., Wongwises S. Effect of fin pitches on the optimum heat transfer performance of crimped spiral fin-and-tube heat exchangers // Int. J. Heat and Mass Trans. 2012. Vol. 55. № 23-24. P. 6555-6566.

4. Кунтыш В.Б., Сухоцкий А.Б., Яцевич А.В. Тепловая эффективность вихревой интенсификации теплоотдачи газового потока при продольном и поперечном обтекании круглотрубных поверхностей часть 2 // Энергетика. Известия высших учебных заведений и энергетических объединений СНГ. 2015. №4. С. 63-74.

5. Хайбуллина А.И., Хайруллин А.Р., Синявин А.А., Ильин В.К. Исследование теплоотдачи в коридорном пучке труб при наложении на поток противоточных несимметричных низкочастотных пульсаций // Современная наука: исследования, идеи, результаты, технологии. 2013. № 1 (12). С. 312-315.

6. Herman C. The Impact of Flow Oscillations on Convective Heat Transfer // Annual Review of Heat Transfer. 2000. Vol. 11. № 11. P. 495-561.

7. Ilyin V.K., Haibullina A.I., Hayrullin A.R., Sabitov L.S External heat transfer in corridor and staggered tube bundles of different configuration under the application of low-frequency pulsations // IOP Conference Series: Materials Science and Engineering. 2017. C. 012- 027.

8. Ilyin V.K., Haibullina A.I., Hayrullin A.R., Sabitov L.S. Thermal and hydraulic efficiency of the corridor tube bundle in conditions of pulsating flow of fluid // IOP Conference Series: Materials Science and Engineering. 2017. C. 012-025. 
9. Molochnikov, V. M., Mikheev, A. N., Aslaev, A. K., Dushina, O. A., Paereliy, A. A. Heat transfer of a tube bundle in a pulsating flow // Thermophysics and Aeromechanics. 2019. 26(4). 547-559.

10. Жукаускас А., Макарявичюс В., Шланчяускас А. Теплоотдача пучков труб в поперечном потоке жидкости / Под ред. А. Жукаускаса - Вильнюс: Минтис, 1968. 192 с. 